\title{
Racial/ethnic disparities in infant mortality
}

\author{
Panagiota Kitsantas ${ }^{1 \%}$ and Kathleen F. Gaffney ${ }^{2}$ \\ ${ }^{1}$ Department of Health Administration and Policy, MS 1J3, \\ George Mason University, College of Health and Human \\ Services, 4400 University Drive, Fairfax, VA 22030, USA \\ ${ }^{2}$ School of Nursing, MS 3C4, George Mason University, \\ College of Health and Human Services, 4400 University \\ Drive, Fairfax, VA 22030, USA
}

\begin{abstract}
Aims: This study examines predictors of neonatal and postneonatal mortality among infants born to black, white, and Hispanic women.

Methods: Linked birth/infant death records from North Carolina for the period 1999-2007 were the source of data. Logistic regression models were constructed to estimate the effect of maternal and infant characteristics on neonatal ( $<28$ days) and postneonatal (28-364 days) mortality.

Results: Analyses revealed no racial/ethnic differences in neonatal mortality, but increased risk among black infants for postneonatal death. Inadequate prenatal care was associated with an increased risk for neonatal mortality across all three racial/ethnic groups. Younger maternal age and lower educational levels were associated with postneonatal deaths for black and white women, but not Hispanic. A previous child loss, being unmarried and labor/delivery complications increased the risk for postneonatal mortality only among white women. Black infants had higher rates of death attributed to sudden infant death syndrome (SIDS), infections, low birth weight (LBW)/prematurity, respiratory conditions, and injuries.

Conclusions: Early initiation of prenatal care, access to riskappropriate obstetric and neonatal services, and participation in intervention programs that support parenting of LBW/preterm infants throughout the first year of life are likely to yield the greatest impact in reducing infant mortality.
\end{abstract}

Keywords: Infant mortality; low birth weight (LBW); neonatal mortality; postneonatal mortality.

\footnotetext{
*Corresponding author:

Panagiota Kitsantas, $\mathrm{PhD}$

Assistant Professor

Department of Health Administration and Policy

MS 1J3

George Mason University

College of Health and Human Services

4400 University Drive

Fairfax

VA 22030

USA

Tel.: + 1 (703) 993-9164

Fax: + 1 (703) 993-1953

E-mail:pkitsant@gmu.edu
}

\section{Introduction}

Progress made over the past two decades to reduce infant mortality rates has now stalled in the USA [17, 18, 34]. The current estimate of 6.71/1000 live births, or 28,000 infant deaths each year, falls short of the Healthy People 2010 goal of 4.5/1000 live births $[18,37]$. Racial/ethnic disparities that have characterized USA infant mortality persist, including a current rate for black infants that is $13.63 / 1000$ live births $[5,19,36]$. To understand racial and ethnic disparities in infant mortality, Hessol and Fuentes-Afflick used the 1995-1997 California linked birth-infant death records to examine neonatal and postneonatal mortality [10]. Similarly, Kitsantas [13] examined maternal characteristics associated with specific causes for infant mortality among black and white women in North Carolina (1989-1997). The present study built upon the findings from these investigations to determine factors associated with racial and ethnic disparities in infant mortality.

North Carolina was selected for study because the state's rate of infant mortality continues to exceed the national average (8.5/1000 live births), despite substantial improvements since 1988 when it had the highest rate in the nation [25]. The state has experienced approximately a 500\% increase in the number of Hispanic births in the past decade [26]. Racial/ ethnic disparities in overall rates of infant mortality in North Carolina mirror national estimates for black, white and Hispanic infants (15.81, 6.36 and 6.61, respectively) [25]. The objective of this study was to identify racial/ethnic differences in predictors of neonatal and postneonatal mortality among infants born in North Carolina, 1999-2007.

\section{Methods}

Data were obtained from the North Carolina linked birth/infant death files from 1999 to 2007, as provided by the North Carolina Center for Health Statistics. All singleton non-Hispanic black, nonHispanic white and Hispanic files with complete data for all study variables were included in the analyses. The study included all liveborn singleton births to black $(n=246,268)$, white $(n=622,610)$, and Hispanic $(\mathrm{n}=142,327)$ women in North Carolina between 1999 and 2007. During this time frame, there were 3107 black, 3162 white, and 750 Hispanic infant deaths.

The outcome variable, infant death (0 and 364 days), was considered as neonatal mortality ( $0-27$ days) or postneonatal mortality (28-364 days). Maternal race/ethnicity was classified as non-Hispanic black, non-Hispanic white, or Hispanic based upon selfreported birth certificate data. Other independent variables included maternal age $(<18,18-26,27-34,>34$ years $)$, maternal education $(<9,9-11,12,13-15,>15$ years), marital status (married/unmarried), adequacy of prenatal care based on Kessner's [12] index (adequate, intermediate and inadequate), parity $(0,1-3,>3)$, previous 
Table 1 Distribution (\%) of maternal and infant characteristics by maternal race/ethnicity.

\begin{tabular}{|c|c|c|c|c|}
\hline & $\begin{array}{l}\text { Black } \\
(n=246,268)\end{array}$ & $\begin{array}{l}\text { White } \\
(\mathrm{n}=622,610)\end{array}$ & $\begin{array}{l}\text { Hispanic } \\
(\mathrm{n}=142,327)\end{array}$ & P-value \\
\hline Maternal age (years) & & & & $<0.001$ \\
\hline$<18$ & 7.3 & 2.7 & 5.2 & \\
\hline $18-26$ & 56.1 & 40.3 & 55.1 & \\
\hline $27-34$ & 28.0 & 43.3 & 32.3 & \\
\hline$>34$ & 8.6 & 13.7 & 7.4 & \\
\hline Maternal education (years) & & & & $<0.001$ \\
\hline$<9$ & 2.1 & 1.7 & 37.0 & \\
\hline $9-11$ & 21.4 & 11.6 & 27.2 & \\
\hline 12 & 38.5 & 28.1 & 32.5 & \\
\hline $13-15$ & 33.8 & 47.0 & 11.2 & \\
\hline$>15$ & 4.2 & 11.6 & 2.1 & \\
\hline Unmarried & 67.7 & 21.6 & 49.4 & $<0.001$ \\
\hline Utilization of prenatal care & & & & $<0.001$ \\
\hline Adequate & 70.5 & 86.5 & 59.2 & \\
\hline Intermediate & 22.1 & 11.0 & 30.9 & \\
\hline Inadequate & 7.4 & 2.5 & 9.9 & \\
\hline Number of previous live births & & & & $<0.001$ \\
\hline 0 & 39.9 & 44.3 & 36.2 & \\
\hline $1-3$ & 31.3 & 35.1 & 31.8 & \\
\hline$>3$ & 28.9 & 20.6 & 31.9 & \\
\hline Previous live births now dead* & 2.2 & 1.2 & 1.7 & $<0.001$ \\
\hline Tobacco use & 10.6 & 16.3 & 1.3 & $<0.001$ \\
\hline $\begin{array}{l}\text { Prior low birth weight or } \\
\text { premature infant* }\end{array}$ & 1.5 & 1.0 & 0.8 & $<0.001$ \\
\hline Anemia & 3.9 & 2.1 & 3.1 & $<0.001$ \\
\hline Diabetes & 2.8 & 2.8 & 2.7 & 0.060 \\
\hline Other medical problems & 30.4 & 24.4 & 21.6 & $<0.001$ \\
\hline Labor/delivery complications & 36.5 & 34.0 & 39.1 & $<0.001$ \\
\hline Female infant & 49.2 & 48.6 & 48.9 & $<0.001$ \\
\hline Birth weight $(\mathrm{g})$ & & & & $<0.001$ \\
\hline Very low, $<1500$ & 3.8 & 1.2 & 1.2 & \\
\hline Moderately low, 1500-2499 & 9.3 & 4.8 & 4.4 & \\
\hline Normal, 2500-4000 & 82.1 & 82.7 & 85.9 & \\
\hline High, $>4000$ & 4.8 & 11.2 & 8.5 & \\
\hline Gestational age (weeks) & & & & $<0.001$ \\
\hline Very premature, $<33$ & 5.2 & 1.8 & 2.0 & \\
\hline Moderately premature, $33-37$ & 12.5 & 8.4 & 9.4 & \\
\hline Term, 38-42 & 78.7 & 86.2 & 84.6 & \\
\hline Post-term, $>42$ & 3.5 & 3.6 & 4.1 & \\
\hline Infant death ( $<365$ days $)$ & 1.3 & 0.5 & 0.6 & $<0.001$ \\
\hline Neonatal death $(<28$ days $)$ & 0.9 & 0.3 & 0.4 & $<0.001$ \\
\hline Postneonatal death (28-364 days) & 0.4 & 0.2 & 0.2 & $<0.001$ \\
\hline
\end{tabular}

*Parous women only.

live births now dead $(0, \geq 1)$, tobacco use (yes/no), anemia (yes/ no), diabetes (yes/no), previous preterm/low birth weight (LBW) infant (yes/no), other medical problems experienced during pregnancy (yes/no) and labor/delivery complications (yes/no). Infant characteristics included gender, birth weight $(<1500,1500-2499$, $2500-4000,>4000 \mathrm{~g})$, and gestational age $(<33,33-37,38-42$, $>42$ weeks). The classification of these variables is based on previous studies [10].

Causes of death were classified according to the ICD-10 classifications [22]. The composition of each cause of death was as follows: congenital anomalies (Q00-Q99); prematurity, LBW (P05-P07); respiratory conditions (P220-P28.9); infections (A00-
B99, P35-P39); sudden infant death syndrome (SIDS) (R95); unintentional injuries (V01-X59, Y85-Y86); intentional injuries (X85-Y09, Y87.1).

Cause-specific neonatal and postneonatal mortality rates were computed for black, white, and Hispanics. $\chi^{2}$ analyses were performed to assess significant differences in the distribution of maternal and infant characteristics across racial/ethnic groups. Separate logistic regression models were constructed for neonatal and postneonatal mortality. Odds ratios (OR) and 95\% confidence intervals (CI) were computed to estimate the effect of maternal and infant characteristics on infant mortality across the three racial/ethnic groups. Analysis was performed using SPSS 16.0 [35]. 
Table 2 Cause-specific death rate (ICD-10) per 100,000 live births for neonatal (N) and postneonatal (P) mortality by maternal race/ ethnicity.

\begin{tabular}{|c|c|c|c|c|c|c|}
\hline \multirow[t]{2}{*}{ Causes of death } & \multicolumn{2}{|l|}{ Black } & \multicolumn{2}{|l|}{ White } & \multicolumn{2}{|l|}{ Hispanic } \\
\hline & $N(n=2158)$ & $P(n=949)$ & $N(n=2025)$ & $P(n=1137)$ & $N(n=513)$ & $P(n=237)$ \\
\hline Congenital anomalies & 118.16 & 52.3 & 92.51 & 32.0 & 120.14 & 47.1 \\
\hline Prematurity/LBW & 295.2 & 4.8 & 61.19 & 1.1 & 89.23 & 2.1 \\
\hline Respiratory conditions & 73.49 & 16.2 & 31.48 & 5.6 & 28.1 & 4.9 \\
\hline Infections & 50.75 & 23.5 & 17.98 & 7.38 & 18.26 & 14.75 \\
\hline SIDS & 7.71 & 106.79 & 8.35 & 59.26 & 1.4 & 23.88 \\
\hline Unintentional injuries & 4.46 & 29.64 & 3.21 & 19.27 & 1.4 & 17.56 \\
\hline Intentional injuries & 0.81 & 13.8 & 0.16 & 5.3 & 1.4 & 7.02 \\
\hline
\end{tabular}

LBW $=$ low birth weight, SIDS $=$ sudden infant death syndrome.

\section{Results}

Table 1 displays the distribution of maternal and infant characteristics by maternal race/ethnicity. Black and Hispanic groups had a significantly higher percentage of teen pregnancies, unmarried mothers, inadequate prenatal care, previous live births, and previous death of a live child than white women. Hispanics had the lowest educational levels, lowest rate of tobacco use, and highest rate of labor and delivery complications. Compared with white and Hispanic women, black mothers were more likely to have anemia or other medical problems during pregnancy. Black mothers had the highest rates of LBW/premature infants and both neonatal and postneonatal infant deaths.

Rates of neonatal and postneonatal cause-specific mortality also differed across racial/ethnic groups (Table 2). Infants born to black women had higher rates of neonatal and postneonatal mortality due to infections, LBW/prematurity, and respiratory conditions. They also had higher rates of postneonatal mortality due to these causes as well as SIDS, unintentional injuries, and intentional injuries.

As displayed in Table 3, no significant racial/ethnic differences were found in neonatal mortality after controlling for maternal and infant characteristics. However, infants born to black mothers had an increased risk for postneonatal mortality. Conversely, infants of Hispanic mothers were significantly less likely to die during the postneonatal period when compared to their white counterparts.

In addition to race/ethnicity, other maternal and child characteristics were associated with an increased risk for infant mortality. Increased risk for neonatal mortality was associated with inadequate prenatal care, having experienced prior death of a living child, labor and delivery complications, very low birth weight (VLBW) and LBW infants and very premature and moderately premature infants. Characteristics associated with postneonatal mortality included lower educational levels, intermediate and inadequate prenatal care, tobacco use, labor and delivery complications, VLBW and LBW infants, and early gestational age. High birth weight lowered the risk for both neonatal and postneonatal mortality. High maternal education lowered the risk for postneonatal mortality only.
White women were at higher risk for neonatal deaths if they had only high school education, had more than three children and experienced a previous child loss (Table 4). Inadequate prenatal care was associated with an increased risk for neonatal mortality across all three racial/ethnic groups. The risk for neonatal deaths was higher for those born $<33$ weeks. Specifically, the odds were higher for infants born to white women $(\mathrm{OR}=4.19)$ compared to black $(\mathrm{OR}=3.65)$ and Hispanic $(\mathrm{OR}=2.75)$. The $\mathrm{OR}$, however, remained approximately the same for all racial/ethnic groups among those born between 33 and 37 weeks. Overall, the risk of neonatal mortality was increased for infants born VLBW or LBW, whereas it decreased for white and black high birth weight infants. The value of the OR for neonatal mortality among VLBW infants born to Hispanic mothers was the highest $(\mathrm{OR}=132.36)$ compared to white $(\mathrm{OR}=$ 49.77) and black mothers $(\mathrm{OR}=73.52)$.

Younger maternal age and lower educational levels were associated with postneonatal deaths for black and white women, but not for Hispanic (Table 5). A previous child loss, being unmarried and labor/delivery complications increased the risk for postneonatal mortality only among white women. Furthermore, intermediate and inadequate levels of prenatal care were associated with postneonatal deaths in white and Hispanic mothers, respectively. Infants born to smokers were more likely to die during the postneonatal period compared to those who were born to non-smokers. Male infants born to black and white women were more likely to die postneonatally. For all racial/ethnic groups, prematurity and LBW increased the risk for infant mortality and high birth weight lowered the risk.

\section{Discussion}

This population-based study of infant deaths in North Carolina between 1999 and 2007 built upon existing studies of the causes and predictors of USA infant mortality. Substantial racial/ethnic differences were found in the maternal and child characteristics that previously have been linked with infant death. After controlling for these characteristics, no significant racial/ethnic differences were found in neonatal 
Table 3 Adjusted odds ratios (95\% CI) for infant mortality.

\begin{tabular}{|c|c|c|}
\hline Risk factors & $\begin{array}{l}\text { Neonatal mortality } \\
(\mathrm{n}=4696)\end{array}$ & $\begin{array}{l}\text { Postneonatal mortality } \\
(\mathrm{n}=2323)\end{array}$ \\
\hline \multicolumn{3}{|l|}{ Maternal race/ethnicity } \\
\hline Black & $1.03(0.96,1.11)$ & $1.26(1.14,1.39)$ \\
\hline Hispanic & $0.99(0.88,1.12)$ & $0.67(0.57,0.79)$ \\
\hline White & 1.00 & 1.00 \\
\hline \multicolumn{3}{|l|}{ Maternal age (years) } \\
\hline$<18$ & $0.94(0.85,1.05)$ & $0.98(0.81,1.18)$ \\
\hline $18-26$ & 1.00 & 1.00 \\
\hline $27-34$ & $0.94(0.86,1.01)$ & $0.66(0.59,0.73)$ \\
\hline$>34$ & $0.95(0.82,1.09)$ & $0.66(0.56,0.77)$ \\
\hline \multicolumn{3}{|l|}{ Maternal education (years) } \\
\hline$<9$ & $1.15(0.98,1.35)$ & $1.73(1.42,2.11)$ \\
\hline $9-11$ & $1.06(0.96,1.18)$ & $1.61(1.41,1.83)$ \\
\hline 12 & $1.09(1.01,1.18)$ & $1.18(1.06,1.33)$ \\
\hline $13-15$ & 1.00 & 1.00 \\
\hline$>15$ & $0.9(0.7,1.0)$ & $0.68(0.52,0.88)$ \\
\hline Unmarried & $1.0(0.9,1.1)$ & $1.09(0.99,1.21)$ \\
\hline \multicolumn{3}{|l|}{ Utilization of prenatal care } \\
\hline Adequate & 1.00 & 1.00 \\
\hline Intermediate & $1.02(0.94,1.11)$ & $1.02(1.01,1.23)$ \\
\hline Inadequate & $1.43(1.29,1.58)$ & $1.07(1.03,1.36)$ \\
\hline \multicolumn{3}{|l|}{ Number of previous live births } \\
\hline 0 & 1.00 & 1.00 \\
\hline $1-3$ & $0.94(0.87,1.02)$ & $1.44(1.23,1.61)$ \\
\hline$>3$ & $1.05(0.96,1.15)$ & $1.88(1.68,2.12)$ \\
\hline Live births now dead & $1.35(1.15,1.57)$ & $1.24(0.98,1.57)$ \\
\hline Tobacco use & $0.91(0.83,0.98)$ & $1.56(1.44,1.77)$ \\
\hline Prior low birth weight or premature infant & $0.75(0.63,0.88)$ & $0.93(0.72,1.19)$ \\
\hline Anemia & $0.94(0.76,1.16)$ & $0.97(0.76,1.25)$ \\
\hline Diabetes & $1.07(0.89,1.29)$ & $1.11(0.86,1.43)$ \\
\hline Other medical problems & $0.86(0.81,0.92)$ & $1.03(0.94,1.13)$ \\
\hline Labor and delivery complications & $1.20(1.13,1.28)$ & $1.13(1.04,1.24)$ \\
\hline Male infant & $1.21(1.11,1.34)$ & $1.31(1.20,1.41)$ \\
\hline \multicolumn{3}{|l|}{ Infant birth weight $(\mathrm{g})$} \\
\hline Very low, $<1500$ & $66.74(56.74,78.51)$ & $10.62(8.57,13.14)$ \\
\hline Moderately low, 1500-2499 & $6.32(5.51,7.25)$ & $3.28(2.88,3.74)$ \\
\hline Normal, 2500-4000 & 1.00 & 1.00 \\
\hline High, $>4000$ & $0.56(0.42,0.76)$ & $0.54(0.42,0.68)$ \\
\hline \multicolumn{3}{|l|}{ Infant gestational age (weeks) } \\
\hline Very premature, $<33$ & $3.74(3.20,4.37)$ & $1.37(1.12,1.69)$ \\
\hline Moderately premature, $33-37$ & $1.52(1.32,1.75)$ & $1.26(1.10,1.43)$ \\
\hline Term, 38-42 & 1.00 & 1.00 \\
\hline Post-term, $>42$ & $0.78(0.54,1.14)$ & $1.02(0.79,1.31)$ \\
\hline
\end{tabular}

$\mathrm{CI}=$ confidence intervals.

mortality. However, racial/ethnic differences in postneonatal mortality continued to be evident.

Hispanics demonstrated the lowest risk for postneonatal mortality, despite low levels of education and prenatal care utilization. This finding substantiates a birth advantage for Hispanic infants compared to black infants with similar socioeconomic characteristics $[2,9,15,16]$. Whereas some have referred to this epidemiological phenomenon as the Hispanic paradox, others raise the question of whether the healthier birth outcomes are associated with characteristics of immigrants, regardless of country of origin. It is theorized that immigrant mothers tend to have more family and partner support, healthier diets, and fewer health risk behaviors, including drug, alcohol and tobacco use than non-immigrants in the USA [15, 16, 24, 27]. Our dataset did not include measures of these factors or information to assess acculturation, such as country of origin, length of stay in the USA, and language spoken at home. Despite other positive birth outcomes, infants born to Hispanic mothers experienced cause-specific neonatal and postneonatal mortality due to congenital anomalies at rates similar to those for black infants and substantially greater than those for white infants. Hessol and Fuentes-Afflick [10] observed a similar racial/ ethnic difference in neonatal mortality related to congenital 
Table 4 Adjusted odds ratios (95\% CI) for neonatal mortality by maternal race/ethnicity.

\begin{tabular}{|c|c|c|c|}
\hline Risk factors & Black & White & Hispanic \\
\hline \multicolumn{4}{|l|}{ Maternal age (years) } \\
\hline$<18$ & $0.94(0.76,1.17)$ & $0.99(0.78,1.26)$ & $0.91(0.60,1.37)$ \\
\hline $18-26$ & 1.00 & 1.00 & 1.00 \\
\hline $27-34$ & $0.98(0.87,1.11)$ & $0.89(0.79,1.10)$ & $0.96(0.76,1.21)$ \\
\hline$>34$ & $0.92(0.77,1.09)$ & $0.99(0.78,1.10)$ & $1.03(0.72,1.46)$ \\
\hline \multicolumn{4}{|l|}{ Maternal education (years) } \\
\hline$<9$ & $1.06(0.75,1.51)$ & $1.06(0.78,1.43)$ & $1.17(0.84,1.64)$ \\
\hline $9-11$ & $0.99(0.85,1.15)$ & $1.10(0.94,1.29)$ & $1.09(0.77,1.55)$ \\
\hline 12 & $1.04(0.93,1.16)$ & $1.17(1.04,1.32)$ & $0.98(0.69,1.39)$ \\
\hline $13-15$ & 1.00 & 1.00 & 1.00 \\
\hline$>15$ & $0.95(0.73,1.25)$ & $0.87(0.72,1.06)$ & $0.63(0.24,1.64)$ \\
\hline Unmarried & $1.02(0.91,1.14)$ & $1.07(0.96,1.21)$ & $0.94(0.77,1.145)$ \\
\hline \multicolumn{4}{|l|}{ Utilization of prenatal care } \\
\hline Adequate & 1.00 & 1.00 & 1.00 \\
\hline Intermediate & $1.04(0.93,1.17)$ & $0.98(0.86,1.14)$ & $1.00(0.81,1.25)$ \\
\hline Inadequate & $1.35(1.17,1.56)$ & $1.66(1.39,1.98)$ & $1.32(1.01,1.72)$ \\
\hline \multicolumn{4}{|l|}{ Number of previous live births } \\
\hline 0 & 1.00 & 1.00 & 1.00 \\
\hline $1-3$ & $0.85(0.76,0.96)$ & $1.01(0.90,1.14)$ & $1.05(0.83,1.33)$ \\
\hline$>3$ & $0.96(0.85,1.10)$ & $1.15(1.08,1.32)$ & $1.06(0.82,1.37)$ \\
\hline Live births now dead & $1.18(0.96,1.46)$ & $1.61(1.24,2.10)$ & $1.51(0.95,2.40)$ \\
\hline Tobacco use & $0.88(0.76,1.02)$ & $0.92(0.82,1.04)$ & $0.61(0.29,1.23)$ \\
\hline $\begin{array}{l}\text { Prior low birth weight or } \\
\text { premature infant }\end{array}$ & $0.78(0.63,0.99)$ & $0.71(0.52,0.95)$ & $0.73(0.41,1.32)$ \\
\hline Anemia & $0.98(0.73,1.31)$ & $0.90(0.63,1.31)$ & $0.89(0.46,1.74)$ \\
\hline Diabetes & $1.01(0.76,1.35)$ & $1.17(0.90,1.54)$ & $0.86(0.45,1.62)$ \\
\hline Other medical problems & $0.84(0.76,0.93)$ & $0.91(0.82,1.01)$ & $0.81(0.66,0.98)$ \\
\hline Labor and delivery complications & $1.17(1.06,1.29)$ & $1.27(1.15,1.41)$ & $1.06(0.87,1.30)$ \\
\hline Male & $1.22(1.11,1.33)$ & $1.21(1.10,1.41)$ & $1.31(1.21,1.42)$ \\
\hline \multicolumn{4}{|l|}{ Infant birth weight (g) } \\
\hline Very low, $<1500$ & $73.52(55.83,96.81)$ & $49.77(39.4,62.87)$ & $132.36(87.39,200.45)$ \\
\hline Low, 1500-2499 & $5.63(4.41,7.17)$ & $5.72(4.72,6.93)$ & $12.24(8.66,17.31)$ \\
\hline Normal, 2500-4000 & 1.00 & 1.00 & 1.00 \\
\hline High, $>4000$ & $0.79(0.41,1.55)$ & $0.57(0.41,0.79)$ & $0.21(0.05,0.86)$ \\
\hline \multicolumn{4}{|l|}{ Infant gestational age (weeks) } \\
\hline Very premature, $<33$ & $3.65(2.81,4.74)$ & $4.19(3.35,5.27)$ & $2.75(1.84,4.09)$ \\
\hline Premature, 33-37 & $1.38(1.07,1.77)$ & $1.57(1.29,1.90)$ & $1.81(1.28,2.56)$ \\
\hline Term, 38-42 & 1.00 & 1.00 & 1.00 \\
\hline Post-term, $>42$ & $0.81(0.39,1.64)$ & $0.63(0.37,1.08)$ & $1.40(0.65,3.03)$ \\
\hline
\end{tabular}

$\mathrm{CI}=$ confidence intervals.

anomalies. Additional study is needed to understand the underpinnings of this disparity.

By contrast to the overall positive birth outcomes of Hispanic, black women experienced higher neonatal mortality with higher cause-specific death rates due to infections, prematurity, LBW and respiratory conditions than their white or Hispanic counterparts. Their proportion of postneonatal mortality was substantially higher and three additional causes of death differentiated this disparity: SIDS, unintentional injuries and intentional injuries. These findings demonstrate a persistent pattern in the problem of infant mortality since the same configuration was identified in previous studies that used the same methodological approaches with populationbased data from a decade earlier in both North Carolina and California [10, 13]. Others also have underscored the disproportionate risk for black infant mortality associated with
SIDS, respiratory conditions, and intentional and unintentional injuries [11, 29, 32].

Progress toward reducing racial/ethnic disparities in infant mortality requires an understanding of underlying risk factors. Advancing maternal age has been proposed as a risk factor for poor birth outcomes among black women, based on the weathering hypothesis which proposes that deterioration in health among black women over the childbearing years occurs as a consequence of living in poverty [7]. Whereas this hypothesis was supported in prior research $[3,6]$, we found no association between age and neonatal mortality. For postneonatal mortality, advancing maternal age appeared to have a protective effect for both black and white mothers. Similarly, previous research has demonstrated a higher risk for infant mortality among young mothers [31]. In our study, younger maternal age was associated with post- 
Table 5 Adjusted odds ratios (95\% CI) for postneonatal mortality by maternal race/ethnicity.

\begin{tabular}{|c|c|c|c|}
\hline Risk factors & Black & White & Hispanic \\
\hline \multicolumn{4}{|l|}{ Age } \\
\hline$<18$ & $0.81(0.60,1.09)$ & $1.07(0.81,1.43)$ & $1.24(0.73,2.09)$ \\
\hline $18-26$ & 1.00 & 1.00 & 1.00 \\
\hline $27-34$ & $0.68(0.57,0.81)$ & $0.60(0.52,0.70)$ & $0.98(0.72,1.34)$ \\
\hline$>34$ & $0.68(0.53,0.87)$ & $0.62(0.49,0.77)$ & $0.87(0.51,1.51)$ \\
\hline \multicolumn{4}{|l|}{ Education } \\
\hline$<9$ & $1.86(1.26,2.77)$ & $2.06(1.52,2.81)$ & $1.60(0.93,2.77)$ \\
\hline $9-11$ & $1.38(1.14,1.68)$ & $1.84(1.52,2.22)$ & $1.69(0.97,2.96)$ \\
\hline 12 & $0.99(0.84,1.18)$ & $1.34(1.14,1.57)$ & $1.34(0.75,2.37)$ \\
\hline $13-15$ & 1.00 & 1.00 & 1.00 \\
\hline$>15$ & $0.78(0.49,1.24)$ & $0.70(0.50,0.97)$ & $0.39(0.05,3.01)$ \\
\hline Not married & $0.88(0.75,1.03)$ & $1.26(1.10,1.45)$ & $1.11(0.85,1.46)$ \\
\hline \multicolumn{4}{|l|}{ Prenatal care } \\
\hline Adequate & 1.00 & 1.00 & 1.00 \\
\hline Intermediate & $0.99(0.85,1.16)$ & $1.23(1.06,1.44)$ & $1.18(0.88,1.58)$ \\
\hline Inadequate & $1.08(0.88,1.34)$ & $1.23(0.96,1.57)$ & $1.51(1.04,2.17)$ \\
\hline \multicolumn{4}{|l|}{ Parity } \\
\hline None & 1.00 & 1.00 & 1.00 \\
\hline $1-3$ & $1.32(1.11,1.56)$ & $1.60(1.38,1.86)$ & $1.21(0.86,1.69)$ \\
\hline$>3$ & $1.84(1.54,2.19)$ & $2.02(1.72,2.38)$ & $1.36(0.94,1.95)$ \\
\hline Live births now dead & $1.06(0.75,1.48)$ & $1.67(1.18,2.36)$ & $0.48(0.15,1.54)$ \\
\hline Tobacco use & $1.65(1.39,1.95)$ & $1.44(1.26,1.65)$ & $2.47(1.28,4.76)$ \\
\hline $\begin{array}{l}\text { Prior low birth weight or } \\
\text { premature infant }\end{array}$ & $0.95(0.67,1.35)$ & $0.88(0.59,1.34)$ & $1.12(0.44,2.81)$ \\
\hline Anemia & $0.92(0.64,1.31)$ & $0.88(0.58,1.34)$ & $1.57(0.85,2.92)$ \\
\hline Diabetes & $0.86(0.55,1.33)$ & $1.18(0.84,1.68)$ & $1.55(0.78,3.05)$ \\
\hline Other medical problems & $1.08(0.94,1.24)$ & $1.00(0.87,1.14)$ & $0.91(0.67,1.22)$ \\
\hline Labor/delivery complications & $1.07(0.94,1.23)$ & $1.16(1.03,1.31)$ & $1.26(0.96,1.64)$ \\
\hline Male infant & $1.22(1.10,1.41)$ & $1.20(1.11,1.34)$ & $1.11(1.10,1.45)$ \\
\hline \multicolumn{4}{|l|}{ Infant birth weight $(\mathrm{g})$} \\
\hline Very low, $<1500$ & $11.79(8.59,16.17)$ & $8.16(5.88,11.31)$ & $17.08(8.87,32.88)$ \\
\hline Moderately low, 1500-2499 & $2.95(2.41,3.61)$ & $3.29(2.73,3.99)$ & $4.97(3.36,7.36)$ \\
\hline Normal, 2500-4000 & 1.00 & 1.00 & 1.00 \\
\hline High, $>4000$ & $0.97(0.65,1.46)$ & $0.46(0.33,0.63)$ & $0.27(0.11,0.75)$ \\
\hline \multicolumn{4}{|l|}{ Infant gestational age (weeks) } \\
\hline Very premature, $<33$ & $1.21(0.88,1.64)$ & $1.62(1.19,2.21)$ & $1.16(0.61,2.24)$ \\
\hline Moderately premature, $33-37$ & $1.14(0.92,1.39)$ & $1.33(1.11,1.60)$ & $1.38(0.94,2.04)$ \\
\hline Term, 38-42 & 1.00 & 1.00 & 1.00 \\
\hline Post-term, $>42$ & $0.92(0.58,1.44)$ & $1.04(0.74,1.46)$ & $1.14(0.56,2.33)$ \\
\hline
\end{tabular}

$\mathrm{CI}=$ confidence intervals.

neonatal deaths for black and white women, but not Hispanics.

Inadequate prenatal care is a previously-established risk factor for infant mortality. In the present study, the risk for neonatal mortality was significantly higher in all groups if they received inadequate prenatal care. Previous studies have shown that late initiation of care in pregnancy is most often associated with sociodemographic factors including living in poor housing conditions $[6,8,20,28,30,33]$. Inadequate prenatal care also has been linked with the lack of access to risk-appropriate care [1]. That is, at-risk mothers may have access to standard, but not the high-risk obstetric and neonatal care that is likely to reduce infant mortality associated with preterm birth and LBW. If data on the number and content of prenatal services utilized by at-risk mothers are made available for future population-based research, the potential for evidence-based recommendations to reduce disparities in infant mortality will be strengthened.

The finding of increased risk for infant death associated with preterm birth and LBW for all racial/ethnic groups mirrors results from previous research. Targeted interventions should be initiated to support mothers with LBW and preterm infants. One empirically-validated intervention for mothers of LBW and preterm infants is the Creating Opportunities for Parent Empowerment (COPE) program [21]. This reproducible educational-behavioral intervention begins early in the NICU, continues throughout the hospital stay, and includes home visitation after discharge. With samples of racially/ethnically diverse mothers of $\mathrm{LBW}$ and preterm infants, it has been shown to improve mental health outcomes (stress, depression and anxiety) and enhance parentinfant interaction. The program prepares parents for the 
appearance and behavioral characteristics of preterm and LBW babies and provides strategies for handling these infants with special home care needs. Future multi-site longitudinal studies of this and similar interventions may lead to reduction of the postneonatal mortality for babies most at-risk.

Several study limitations are recognized. The potential for some inaccuracies in birth certificate data, such as prenatal care utilization and medical conditions exists with this dataset. However, the reliability and validity of other birth certificate information, including birth weight, has been reported [4]. Under estimates of some self-reported information, such as tobacco use also may have occurred as the result of a social desirability response bias. Further, our findings represent only one state and may not, therefore, be generalized nationally. Finally, the use of linked infant birth/ death records does not allow for the measurement of quality of prenatal care, access to high-risk obstetric and neonatal care, and psychosocial factors that may lead to poor birth outcomes.

The findings of this study mirror national trends that show persistent racial/ethnic disparities in infant mortality, LBW, and preterm births $[14,23]$. Public health policies are needed that recognize these continuing racial/ethnic disparities and support research and practice aimed at the early initiation of prenatal care, access to risk-appropriate obstetric and neonatal services, and intervention programs that support mothers of LBW and preterm infants throughout the first year of life.

\section{Acknowledgments}

We would like to thank the State Center for Health Statistics (SCHS) and the Howard W. Odum Institute for Research in Social Science at University of North Carolina at Chapel Hill for providing these data. These agencies are responsible for the original data only, and not for the content of the current study.

\section{References}

[1] Alexander GR, Wingate MS, Bader D, Kogan MD. The increasing racial disparity in infant mortality rates: composition and contributors to recent US trends. Am J Obstet Gynecol. 2008;198:51e1-9.

[2] Brown HL, Chireau MV, Jallah Y, Howard D. The "Hispanic paradox": an investigation of racial disparity in pregnancy outcomes at a tertiary care medical center. Am J Obstet Gynecol. 2007;197:197e1-9.

[3] Buescher PA, Mittal M. Racial disparities in birth outcomes increase with maternal age: recent data from North Carolina. NC Med J. 2006;67:16-20.

[4] Buescher PA, Taylor KP, Davis MH, Bowling MJ. The quality of the new birth certificate data: a validation study in North Carolina. Am J Public Health. 1993;83:1163-5.

[5] Centers for Disease Control and Prevention. Racial/ethnic disparities in infant mortality - United States, 1995-2002. MMWR Morb Mortal Wkly Rep. 2005;54:553-6.
[6] Collins JW, Wambach J, David RJ, Ranking KM. Women's lifelong exposure to neighborhood poverty and LBW: a population-based study. Matern Child Health J. 2009;13:326-33.

[7] Geronimus A. The weathering hypothesis and the health of African-American women and infants: evidence and speculations. Ethnic Dis. 1992;2:207-21.

[8] Hearst MO, Oakes M, Johnson PJ. The effect of racial residential segregation on black infant mortality. Am J Epidemiol. 2008; 168:1247-54.

[9] Hessol NA, Fuentes-Afflick E. The perinatal advantage of Mexican-origin Latina women. Ann Epidemiol. 2000;10: 516-23.

[10] Hessol NA, Fuentes-Afflick E. Ethnic differences in neonatal and postneonatal mortality. Pediatrics. 2005;115:e44-51. URL: www.pediatricsorg/chi/doi/10.1542/peds.2004-04781.

[11] Jain A, Khoshnood B, Lee KS, Concato J. Injury related infant death: the impact of race and birth weight. Inj Prev. 2001; 7:135-40.

[12] Kessner DM, Singer J, Kalk CE, Schlesinger ER. Infant death: an analysis by maternal risk and health care. Washington, DC: Institute of Medicine; 1973.

[13] Kitsantas P. Ethnic differences in infant mortality by cause of death. J Perinatol. 2008;28:573-9.

[14] Leigh WA, Wheatley AL. Trends in child health 1997-2006: assessing racial/ethnic disparities in low birthweight. Washington, DC: Joint Center for Political and Economic Studies; 2009.

[15] Leslie JC, Diehl SJ, Galvin SL. A comparison of birth outcomes among US-born and non-US-born Hispanic women in North Carolina. Maternal Child Health J. 2006;10:33-8.

[16] Leslie JC, Galvin SL, Diehl SJ. Infant mortality, LBW, and prematurity among Hispanic, white and African American women in North Carolina. Am J Obstet Gynecol. 2003;188: $1238-40$.

[17] Levi J, Cimons M, Johnson K. Healthy women, healthy babies: an issue brief from trust for America's Health. 2008. www.healthyamericans.org.

[18] MacDorman MF, Mathews TJ. Recent trends in infant mortality in the United States. NCHS data brief, no 9. Hyattsville, MD: National Center for Health Statistics; 2008.

[19] Mathews TJ, MacDorman MF. Infant mortality statistics from the 2005 period linked birth/infant death data set. National vital statistics reports; vol 57 no 2. Hyattsville, MD: National Center for Health Statistics; 2008.

[20] McCowan LME, Dekker GA, Chan E, Stewart A, Chappell LC, Hunter M, et al. Spontaneous preterm birth and small for gestational age infant in women who stop smoking early in pregnancy: prospective cohort study. Br Med J. 2009;338: b1080. pp 1-6.

[21] Melnyk BM, Feinstein NF, Alpert-Gillis L, Fairbanks E, Crean HF, Sinkin RA, et al. Reducing premature infants' length of stay and improving parents' mental health outcomes with the Creating Opportunities for Parent Empowerment (COPE) Neonatal Intensive Care Unit Program: a randomized, controlled trial. Pediatrics. 2006;118:e1414-27.

[22] National Center for Health Statistics. Instruction manual part 9: ICD-10 cause of death lists for tabulating mortality statistics, effective 1999. Hyattsville, Maryland: National Center for Health Statistics; 1999.

[23] National Center for Health Statistics. Overall infant mortality rate in U.S. largely unchanged. News Release, May 2, 2007, http://www.cdc.gov/nchs/pressroom/o7newsreleases/infantmortality.htm. 
[24] Nichols, JE. Response to: Brown HL, Chireau MV, Jallah Y, Howard D. The "Hispanic paradox": an investigation of racial disparity in pregnancy outcomes at a tertiary care medical center. Am J Obstet Gynecol. 2007;197:197e1-9.

[25] North Carolina Department of Health and Human Services State Center for Health Statistics, 30 Jul 2008. http:// www.schs.state.nc.us/SCHS/deaths/ims/2007.

[26] North Carolina Division of Public Health. Racial and ethnic differences in health in North Carolina. Executive summary from a special report from the Center for Health Informatics and Statistics and Office of Minority Health. 2000:1-26.

[27] Page RL. Positive pregnancy outcomes in Mexican immigrants: what can we learn? J Obstet Gynecol Neonatal Nurs. 2004;33:783-90.

[28] Pagnini DL, Reichman NE. Psychosocial factors and the timing of prenatal care among women in New Jersey's HealthStart program. Fam Plann Perspect. 2000;32:5664.

[29] Papacek EM, Collins JW, Schulte NF, Goergen C, Drolet A. Differing postneonatal mortality rates of African-American and white infants in Chicago: an ecological study. Maternal Child Health J. 2002;6:99-105.

[30] Paul DA, Mackley A, Locke RG, Stefano JL, Kroelinger C. State infant mortality: an ecologic study to determine modifiable risks and adjusted infant mortality rates. Maternal Child Health J. 2009;13:343-8.
[31] Phipps MG, Blume JD, DeMonner SM. Young maternal age associated with increased risk of postneonatal death. Obstet Gynecol. 2002;100:481-6.

[32] Ranganathan D, Wall S, Khosbnood B, Singh JK, Lee K. Racial differences in respiratory-related neonatal mortality among very LBW infants. J Pediatr. 2000;136:454-9.

[33] Sims M, Rainge Y. Urban poverty and infant-health disparities among African-American and whites in Milwaukee. J Natl Med Assoc. 2002;94:472-9.

[34] Singh GK, Kogan MD. Persistent socioeconomic disparities in infant, neonatal, and postneonatal mortality rates in the United States, 1969-2001. Pediatrics. 2007;119:e928-39.

[35] SPSS (2007). SPSS Inc Release 16.0 edition. Chicago, Il: SPSS Inc.

[36] The Annie E. Casey Foundation. 2008 Kids count data book: state profiles of child well-being. Baltimore, MD: The Annie E. Casey Foundation, June 2008: p. 29.

[37] U.S. Department of Health and Human Services. Healthy people 2010. 2nd ed. With understanding and improving health and objectives for improving health, 2 vols. Washington, DC: U.S. Government Printing Office, November 2000.

The authors stated that there are no conflicts of interest regarding the publication of this article.

Received July 15, 2009. Accepted August 12, 2009. 